\title{
Screening of the Cervidae family in Poland for Mycoplasma species
}

\author{
Katarzyna Dudek ${ }^{1}$, Dariusz Bednarek ${ }^{1}$, Ewelina Szacawa ${ }^{1}$, Roger D. Ayling ${ }^{2}$ \\ ${ }^{1}$ Department of Cattle and Sheep Diseases, \\ National Veterinary Research Institute, 24-100 Pulawy, Poland \\ ${ }^{2}$ Animal and Plant Health Agency, Addlestone, Surrey KT15 3NB, UK \\ katarzyna.dudek@piwet.pulawy.pl
}

Received: June 1, 2016

Accepted:November 16, 2016

\begin{abstract}
Introduction: Several Mycoplasma species can cause severe diseases in ruminant hosts, some of which are the diseases listed by the World Organisation for Animal Health (OIE). The role of the Cervidae family in carrying and transmitting ruminant mycoplasma infections in Poland is unknown. Material and Methods: Antibody and antigen detection tests for the main mycoplasma species that can affect wild ruminants were performed on 237 samples (serum, nasal swab, bronchoalveolar lavage, and lung) collected from 161 animals during 2011-2014. The samples were obtained from a cull of healthy population of deer which included: 96 red deer (Cervus elaphus elaphus), 19 fallow deer (Dama dama), and 46 roe deer (Capreolus capreolus). Results: Serological screening tests revealed positive reactions to Mycoplasma bovis in one sample and to Mycoplasma capricolum subsp. capripneumoniae in three samples; however, these three samples were negative by immunoblotting. Other antibody and antigen detection tests demonstrated negative results. Conclusion: Currently wild cervids in Poland do not play a significant role in transmitting mycoplasma infections to domestic animals, but they remain a potential risk.
\end{abstract}

Keywords: Cervidae family, ruminant mycoplasmas, epidemiology, testing, Poland.

\section{Introduction}

Several Mycoplasma species can cause severe diseases in ruminant hosts, some of which are the diseases listed by the World Organisation for Animal Health (OIE). This includes contagious caprine pleuropneumonia (CCPP) caused by Mycoplasma capricolum subsp. capripneumoniae (Mccp) (15). CCPP has also been found in wild small ruminants such as wild goat (Capra aegagrus), Nubian ibex (Capra ibex nubiana), Larisstan mouflon (Ovis orientalis laristanica), Gerenuk (Litocranius walleri), and Gazelles, resulting in some cases in animal mortality $(1,13)$. With CCPP being present in the Thrace region of Turkey (17), there is a risk that wildlife could spread the disease across Europe. Contagious agalactia (CA) is also an OIE-listed disease in small ruminants, causing mastitis, keratoconjunctivitis, and arthritis (16). Mycoplasma agalactiae, the main causative agent of CA, was isolated from Spanish ibex (Capra pyrenaica hispanica) (9) and detected in roe deer (2). Mycoplasma arginini was also detected in Spanish ibex (9) and bighorn sheep (Ovis canadensis) causing, among others aetiological agents, fatal pneumonia (19). In Poland, specific antibodies to M. agalactiae have not been detected in domestic sheep and goats (5), whereas the epizootic situation for Mccp is not known.

Due to a lack of data about prevalence of pathogenic mycoplasmas in wild small ruminants in Poland, the aim of the study was to examine whether Polish population of Cervidae family is a potential reservoir of these pathogens for domestic animals.

\section{Material and Methods}

Animals and samples. Between 2011 and 2014, samples were obtained from 161 deer, of which 96 were red deer (Cervus elaphus elaphus), 19 fallow deer (Dama dama), and 46 roe deer (Capreolus capreolus), culled according to Polish hunting law requirements. The 
animals came from five regions of Poland: north-western $(n=41)$, northern $(n=42)$, south-western $(n=19)$, eastern $(\mathrm{n}=43)$, and central $(\mathrm{n}=16)$. Two hundred and thirty seven samples comprising 119 sera, 22 nasal swabs, 80 bronchoalveolar lavages (BALs), and 16 lung samples were examined (Table 1). The samples were delivered directly to the National Veterinary Research Institute in Pulawy and stored at $-20 \pm 5^{\circ} \mathrm{C}$ until examination.

Serological methods. The following tests were used for serological diagnosis: M. agalactiae Antibody Test Kit (IDEXX, France); latex agglutination test for contagious caprine pleuropneumonia (CCPP) (CapriLAT, APHA, $\mathrm{UK}$ ); $M$. bovis ELISA kit Sero (Bio-X Diagnostics, Belgium); and three kits for contagious bovine pleuropneumonia (CBPP) caused by Mycoplasma mycoides subsp. mycoides (Mmm): Mmm Antibody Test Kit (IDEXX, France), complement fixation test (CFT) (CIRAD, France), and latex agglutination test (BoviLAT, APHA, UK). The suitability of using these tests in deer was confirmed by the manufacturers. The $M$. agalactiae Antibody Test Kit has an anti-ruminant IgG conjugate and detects Bovidae, Cervidae, and Camelidae antibodies. The $M$. bovis ELISA kit has a protein $\mathrm{G}$ conjugate which is suitable for deer samples. The Mmm antibody Test Kit is monoclonal-based and therefore has an anti-mouse conjugate and is not dependent on the tested species. The CFT for CBPP requires heat inactivation of the host species complement which is replaced by guinea pig complement and the test is therefore not host speciesspecific. The latex agglutination tests directly bind antigen to antibody and are not host-specific; therefore all tests used are also suitable for testing deer sera.
A specific immunoblotting method, which used a protein $G$ conjugate and had previously confirmed CCPP positive deer in the UAE, was used as a confirmatory test for $M c c p$ (14).

Molecular methods. DNA was extracted from nasal swabs, BAL, or lung tissue using the QIAmp DNA Mini Kit (Qiagen, Germany) according to manufacturer's instructions. The PCR/denaturing gradient gel electrophoresis (PCR/DGGE) method (12) with modifications (4) was used to detect and identify the main ruminant mycoplasmas. The following controls were used: DNA from the reference strain of $M$. bovis (ATCC 25523) and NCTC type strains of M. agalactiae, Mccp, M. mycoides subsp. capri, M. bovirhinis, M. dispar, M. arginini, $M$. canis, Mmm, M. canadense, and M. alkalescens, obtained from the Animal Plant and Health Agency, Weybridge, UK.

M. bovis antigen detection. The Pulmotest Mycoplasma bovis ELISA kit (Bio-X Diagnostics, Belgium) was used to detect $M$. bovis antigen from nasal swabs, BAL, and lung samples. This kit uses a culture enrichment step on Hayflick medium and specific polyclonal antibodies to detect $M$. bovis.

\section{Results}

Serological screening of cervids demonstrated one strong positive sample, with a calculated degree of positivity of $90.8 \%$ for $M$. bovis in roe deer, which originated from the north-western region of Poland (Table 1).

Table 1. Detailed data of deer with positive serological results for $M$. bovis and contagious caprine pleuropneumonia (CCPP)

\begin{tabular}{|c|c|c|c|c|c|}
\hline \multirow{2}{*}{ Region } & \multirow{2}{*}{ Total deer sampled } & \multirow{2}{*}{ Sample type } & Red deer $(n=24)$ & Roe deer $(n=14)$ & Fallow deer $(\mathrm{n}=3)$ \\
\hline & & & \multicolumn{3}{|c|}{ Number of samples tested } \\
\hline \multirow{4}{*}{ north-western } & \multirow{4}{*}{41} & serum & 24 & 14 (1 M. bovis ELISA positive) & 3 \\
\hline & & BAL & 11 & 10 & 2 \\
\hline & & lung & 1 & 0 & 0 \\
\hline & & nasal swabs & 0 & 2 & 0 \\
\hline \multirow{6}{*}{ northern } & \multirow{6}{*}{42} & \multirow{2}{*}{ Sample type } & Red deer $(n=30)$ & Roe deer $(n=5)$ & Fallow deer $(n=7)$ \\
\hline & & & \multicolumn{3}{|c|}{ Number of samples tested } \\
\hline & & serum & 18 & 5 & 0 \\
\hline & & BAL & 11 & 1 & 5 \\
\hline & & lung & 1 & 1 & 1 \\
\hline & & nasal swabs & 12 & 0 & 7 \\
\hline \multirow{6}{*}{ south-western } & \multirow{6}{*}{19} & \multirow{2}{*}{ Sample type } & Red deer $(n=8)$ & Roe deer $(n=9)$ & Fallow deer $(\mathrm{n}=2)$ \\
\hline & & & \multicolumn{3}{|c|}{ Number of samples tested } \\
\hline & & serum & 8 & 9 & 2 \\
\hline & & BAL & 7 & 2 & 1 \\
\hline & & lung & 1 & 2 & 1 \\
\hline & & nasal swabs & 0 & 0 & 0 \\
\hline \multirow{6}{*}{ eastern } & \multirow{6}{*}{43} & \multirow{2}{*}{ Sample type } & Red deer $(\mathrm{n}=28)$ & Roe deer $(\mathrm{n}=8)$ & Fallow deer $(n=7)$ \\
\hline & & & \multicolumn{3}{|c|}{ Number of Samples tested } \\
\hline & & serum & 20 (3 CCPP CapriLAT positive) & 4 & 7 \\
\hline & & BAL & 17 & 5 & 0 \\
\hline & & lung & 0 & 1 & 0 \\
\hline & & nasal swabs & 1 & 0 & 0 \\
\hline \multirow{6}{*}{ central } & \multirow{6}{*}{16} & \multirow{2}{*}{ Sample type } & Red deer $(n=6)$ & Roe deer $(n=10)$ & Fallow deer $(\mathrm{n}=0)$ \\
\hline & & & \multicolumn{3}{|c|}{ Number of samples tested } \\
\hline & & serum & 0 & 5 & 0 \\
\hline & & BAL & 4 & 4 & 0 \\
\hline & & lung & 2 & 5 & 0 \\
\hline & & nasal swabs & 0 & 0 & 0 \\
\hline
\end{tabular}


No serological confirmatory tests were performed with this sample. In addition, the CapriLAT displayed $1+$ to $2+$ agglutination (maximum $3+$ ) in three red deer which originated from eastern region of Poland (Table 1). However, these were negative by the more specific confirmatory immunoblot test. M. agalactiae and $\mathrm{Mmm}$ antibody detection tests demonstrated negative results. Molecular tests (PCR/DGGE) did not identify any ruminant Mycoplasma species and no M. bovis was detected using the Pulmotest Mycoplasma bovis ELISA kit.

\section{Discussion}

Houshaymi et al. (11) demonstrated that the CapriLAT test was more sensitive than the CCPP CFT (15). It is known that the CFT may give false positive reactions caused by cross-reactions with other members of the Mycoplasma mycoides cluster, e.g. M. mycoides subsp. capri or $\mathrm{Mmm}$, due to the use of crude antigen in the test $(3,15)$; however, positive samples in the CapriLAT always require a confirmation using other tests (14). Three positive results obtained in this study in the CapriLAT test proved to be negative by immunoblotting. Bison can be infected with $M$. bovis (18). Previously, six sera with specific antibodies to M. bovis were found in European bison (Bison bonasus) which came from Eastern Poland and had gross lung lesions typical of M. bovis infection (6). Cervids have been reported to be infected with haemoplasmas (10), M. bovis (7), M. agalactiae (2), $M$. conjunctivae (8), and Mccp (1). This indicates that there is a risk that wildlife animals may carry and transmit Mycoplasma species that are infectious to domestic ruminants. In this study the M. bovis seropositive roe deer did not have lung lesions associated with mycoplasma infections, so this result might be a false-positive result. However, it could also be due to contact with the pathogen, or a carrier animal prior to development of serious infection and visible gross lesions, or due to cross-reactions with other bacterial or even mycoplasma species. Serological tests are a useful and cost-effective approach to screening a large number of samples for Mycoplasma infections; however, positive serological results should be confirmed by other methods. The PCR/DGGE method is a sensitive test and if profiles obtained do not match the controls, further identifications, additional controls, or sequencing should be performed. However, in this case no other Mycoplasma species were detected. Generally, more reliable results in this kind of study can be obtained when fresh lung samples with pulmonary tissue lesions are used. Nevertheless, during studies on wild animals under field conditions, in which more Mycoplasma species positive samples may be detected, it is often impossible due to the present restricted hunting regulations of Poland. Therefore, it is not possible to totally exclude the risk of cervids carrying Mycoplasma species. Thus the conclusion from this study is that currently the Polish population of Cervidae family is not a major reservoir of infection with pathogenic mycoplasma species for domestic animals.

Conflict of Interests Statement: The authors declare that there is no conflict of interests regarding the publication of this article.

Financial Disclosure Statement: The study was supported by Project NR12-0126-10/2011 funded by the Ministry of Science and Higher Education.

Animal Rights Statement: None required.

\section{References}

1. Arif A., Schulz J., Thiaucourt F., Taha A., Hammer S.: Contagious caprine pleuropneumonia outbreak in captive wild ungulates at Al Wabra Wildlife Preservation, State of Qatar. J Zoo Wildl Med 2007, 38, 93-96.

2. Candela M.G., Serrano E., Sevila J., León L., Caro M.R., Verheyden H.: Pathogens of zoonotic and biological importance in roe deer (Capreolus capreolus): Seroprevalence in an agrosystem population in France. Res Vet Sci 2014, 96, 254-259.

3. Cottew G.S., Breard A., DaMassa A.J., Ernø H., Leach R.H., Lefevre P.C., Rodwell A.W., Smith G.R.: Taxonomy of the Mycoplasma mycoides cluster. Isr J Med Sci 1987, 23, 632-635.

4. Dudek K., Bednarek D., Ayling R.D., Kycko A., Szacawa E., Karpińska T.A.: An experimental vaccine composed of two adjuvants gives protection against Mycoplasma bovis in calves. Vaccine 2016, 34, 3051-3058.

5. Dudek K., Bednarek D., Szacawa E.: Mycoplasma mycoides subsp. mycoides small colony variant and Mycoplasma agalactiae antibodies in ruminants in Poland. Bull Vet Inst Pulawy 2012, 56, 453-457.

6. Dudek K., Bednarek D., Szacawa E., Ayling R.D., Krzysiak M.K., Marczuk J.: A serological and molecular study on the occurrence of mycoplasmas in European bison (Bison bonasus) from two areas of Eastern Poland. Pol J Vet Sci 2015, 18, 881883.

7. Dyer N.W., Krogh D.F., Schaan L.P.: Pulmonary mycoplasmosis in farmed white-tailed deer (Odocoileus virginianus). J Wildl Dis 2004, 40, 366-370.

8. Gaffuri A., Giacometti M., Tranquillo V.M., Magnino S., Cordioli P., Lanfranchi P.: Serosurvey of roe deer, chamois and domestic sheep in the central Italian Alps. J Wildl Dis 2006, 42, 685-690.

9. González-Candela M., Cubero-Pablo M.J., Martín-Atance P., León-Vizcaíno L.: Potential pathogens carried by Spanish ibex (Capra pyrenaica hispanica) in southern Spain. J Wildl Dis 2006, 42, 325-334

10. Grazziotin A.L., Duarte J.M., Szabó M.P., Santos A.P., Guimarães A.M., Mohamed A., Vieira R.F., de Barros Filho I.R., Biondo A.W., Messick J.B.: Prevalence and molecular characterization of Mycoplasma ovis in selected free-ranging Brazilian deer populations. J Wildl Dis 2011, 47, 1005-1011.

11. Houshaymi B., Tekleghiorghis T., Wilsmore A.J., Miles R.J., Nicholas R.A.: Investigations of outbreaks of contagious caprine pleuropneumonia in Eritrea. Trop Anim Health Prod 2002, 34, 383-389.

12. McAuliffe L., Ellis R.J., Lawes J.R., Ayling R.D, Nicholas R.A.: 16S rDNA PCR and denaturing gradient gel electrophoresis; a single generic test for detecting and differentiating Mycoplasma species. J Med Microbiol 2005, 54, 731-739. 
13. Nicholas R., Ayling R., McAuliffe L.: Mycoplasma diseases of ruminants, CAB International, Wallingford, 2008.

14. Nicholas R., Churchward C.: Contagious caprine pleuropneumonia: new aspects of an old disease. Transbound Emerg Dis 2012, 59, 189-196.

15. OIE: Contagious caprine pleuropneumonia. In: Manual of Diagnostic Tests and Vaccines for Terrestrial Animals, Chapter 2.7.6., OIE, Paris, 2012, pp. 995-1007.

16. OIE: Contagious agalactia. In: Manual of Diagnostic Tests and Vaccines for Terrestrial Animals, Chapter 2.7.5., OIE, Paris, 2012, pp. 987-994

17. Ozdemir U., Loria G.R., Godinho K.S., Samson R., Rowan T.G., Churchward C., Ayling R.D., Nicholas R.A.: Effect of danofloxacin (Advocin A180) on goats affected with contagious caprine pleuropneumonia. Trop Anim Health Prod 2006, 38, 533-540.

18. Suleman M., Prysliak T., Clarke K., Burrage P., Windeyer C., Perez-Casal J.: Mycoplasma bovis isolates recovered from cattle and bison (Bison bison) show differential in vitro effects on PBMC proliferation, alveolar macrophage apoptosis and invasion of epithelial and immune cells. Vet Microbiol 2016, 186, 28-36.

19. Woolf A., Kradel D.C.: Mortality in captive bighorn sheepclinical, hematological, and pathological observations. J Wildl Dis $1973,9,12-17$. 